\title{
On the Impact of the Results of WRC 2019 on THz Communications
}

\author{
Thomas Kürner ${ }^{1}$, Akihiko Hirata ${ }^{2}$ \\ ${ }^{1}$ Technische Universität Braunschweig, Institut für Nachrichtentechnik, Braunschweig, Germany \\ ${ }^{2}$ Chiba Institute of Technology, Japan \\ t.kuerner@tu-bs.de; hirata.akihiko@p.chibakoudai.jp
}

\begin{abstract}
This contribution describes and assesses the outcome of WRC 2019 w.r.t. THz communications. WRC 2019 has included a new footnote to the radio regulations, which describes the conditions for the use of the spectrum between 275 and 450 $\mathrm{GHz}$ by land mobile and fixed service. Totally, $160 \mathrm{GHz}$ of spectrum are now available for $\mathrm{THz}$ communications, where no specific conditions are necessary to protect EESS. This provides a sound basis for the future implementation of $\mathrm{THz}$ communications. Furthermore, the paper identifies a couple of future regulatory and standardization activities.
\end{abstract}

Keywords-THz Communications; Regulation; WRC 2019

\section{INTRODUCTION}

In 2017, IEEE 802 has published IEEE Std. 802.15.3d-2017, the first wireless standard for fixed point-to-point links operating at carrier frequencies between 252 and $321 \mathrm{GHz}$ [1] with channel bandwidths between $2.16 \mathrm{GHz}$ and $69.12 \mathrm{GHz}$. The global use of any radio system requires the availability of spectrum. Hence, the development of IEEE Std. 802.15.3d2017 has been based on the 2016 version of the Radio Regulations (RR) [2]. The RR include an allocation of the bands from 252 to $275 \mathrm{GHz}$ for the use by land mobile and fixed service on a co-primary basis. For the frequency bands beyond $275 \mathrm{GHz}$, no specific allocation to any radio service has been defined. Instead, a footnote 5.565 defines bands between 275 and $1000 \mathrm{GHz}$, where passive services such as earth exploration satellite service (EESS) and radio astronomy (RA) have to be protected from harmful interference by any active service, such as $\mathrm{THz}$ communications operated in the same bands. A closer look at these bands reveals that almost all bands above $275 \mathrm{GHz}$ are in potential use by either EESS or RA. Hence, any use of spectrum beyond $275 \mathrm{GHz}$ for $\mathrm{THz}$ communications with bandwidths of up to several tens of $\mathrm{GHz}$ as in [1] is possible only if the spectrum is shared with at least one of the above mentioned passive services. Footnote 5.565 further states that "administrations wishing to make frequencies in the 275-1000 $\mathrm{GHz}$ range available for active service applications are urged to take all practicable steps to protect these passive services from harmful interference". In a worst-case scenario, this could lead to different decisions in different countries [3]. In order to address this problem, the World Radiocommunication Conference WRC 2015 had invited ITU-R to perform "Studies towards an identification for use by administrations for landmobile and fixed services applications operating in the frequency range $275-450 \mathrm{GHz}$ " [4], with the goal to define more detailed rules at the World Radiocommunication Conference (WRC) 2019 under its AI (agenda item) 1.15. This has triggered activities towards sharing studies, which have been finished before the opening of WRC 2019. The focus on these sharing studies in terms of passive services has been on EESS [3,5,6,7], since earlier studies [8,9] have already identified EESS as the more critical service due to its operational characteristics, whereas RA with its large antennas typically located in very remote area and pointing up the sky can be protected by simple measures like a minimum distance of the $\mathrm{THz}$ communication device to the RA antenna. This paper presents the results of WRC 2019 w.r.t. $\mathrm{THz}$ communications, discusses briefly its implications and gives a short outlook towards the next steps. The paper is organized as follows: The following section II. describes the outcome of WRC 2019 and a summary of the available frequency bands for $\mathrm{THz}$ communications is given in section III. An assessment of the WRC 2019 outcome and a description of potential activities towards future WRCs is provided in section IV. Conclusions are provided in section $\mathrm{V}$.

\section{OUTCOME OF WRC 2019}

The outcome is described in the Final Acts of WRC 2019 [10]. As far as AI 1.15 is concerned a new footnote 5.564A has been introduced, which contains four key items:

1. In total, $137 \mathrm{GHz}$ in the band 275 to $450 \mathrm{GHz}$ have been identified for use for land mobile and fixed service, where sharing with EESS is possible and no specific conditions are necessary to protect EESS.

2. The remaining $38 \mathrm{GHz}$ of spectrum may only be used by fixed and land mobile service applications when specific conditions to ensure the protection of Earth exploration-satellite service (passive) applications have been determined in accordance with Resolution 731 (Rev.WRC-19), which deals with the consideration of sharing and adjacent-band compatibility between passive and active services above $71 \mathrm{GHz}$, are met. Resolution 731“ invites ITU$\mathrm{R}$ to conduct studies to determine the specific conditions to be applied to the land mobile and fixed service applications to ensure the protection of Earth exploration-satellite service (passive) applications in 
the frequency bands $296-306 \mathrm{GHz}, 313-318 \mathrm{GHz}$ and 333-356 GHz.

3. For the whole frequency band $275-450 \mathrm{GHz}$, specific conditions to protect radio astronomy service may apply. Such conditions are for example a minimum distance and/or avoidance angles.

4. The use of the identified bands for land mobile service and fixed service does not preclude the use of the bands by other application or radio service. Such services are for example radar or imaging applications. With its resolution, COM6/19 (WRC-19) has defined a preliminary agenda for the WRC 2027, on the identification of spectrum for radio location applications in frequency bands in the range 275-700 $\mathrm{GHz}$ for millimetre and sub-millimetre wave imaging systems.

\section{TOTAL AVAILABLE SPECTRUM FOR THz COMMUNICATIONS}

Together with the already allocated spectrum between 252 and $275 \mathrm{GHz}$, totally $160 \mathrm{GHz}$ of spectrum are available for $\mathrm{THz}$ communications in the whole frequency band between 275 and $450 \mathrm{GHz}$ with no specific conditions necessary to protect EESS. All details and the bands and the conditions for their use by $\mathrm{THz}$ communications are provided in Table 1.

Table 1 Overview of available Spectrum for $\mathrm{THz}$ Communications

\begin{tabular}{|c|l|}
\hline Frequency in GHz & \multicolumn{1}{|c|}{ Status in Radio Regulations } \\
\hline $252-275$ & $\begin{array}{l}\text { Allocation for land mobile and fixed } \\
\text { service on a co-primary basis [2] }\end{array}$ \\
\hline $275-296$ & $\begin{array}{l}\text { Identification for use for the } \\
\text { implementation of land mobile and fixed } \\
\text { service according to FN 5.564A. } \\
\text { No specific conditions are necessary to } \\
\text { protect Earth exploration-satellite service } \\
\text { (passive) applications [10]. }\end{array}$ \\
\hline $306-313$ & $\begin{array}{l}\text { may only be used by fixed and land } \\
\text { mobile service applications when } \\
\text { specific conditions to ensure the } \\
\text { protection of Earth exploration-satellite } \\
\text { service (passive) applications are } \\
\text { determined in accordance with } \\
\text { Resolution 731 (Rev.WRC-19) [10]. }\end{array}$ \\
\hline $356-450$
\end{tabular}

\section{ASSESSMENT OF THE WRC 2019 OUTCOME}

The outcome of WRC 2019 provides a sound regulatory framework for the implementation of future $\mathrm{THz}$ communication systems in the frequency band 252 to $450 \mathrm{GHz}$. Within this band, four contiguous bands with bandwidths of 44 $\mathrm{GHz}$ (between 252 and $296 \mathrm{GHz}$ ), $7 \mathrm{GHz}$ (between 306 and 313 $\mathrm{GHz}$ ), $15 \mathrm{GHz}$ (between 318 and $333 \mathrm{GHz}$ ) and $94 \mathrm{GHz}$ (between 356 and $450 \mathrm{GHz}$ ) are available. Due to its atmospheric conditions, the band 252 to $296 \mathrm{GHz}$ is favorable for fixed outdoor links with several hundred meters link distances. The other three bands can be also used for example for short range indoor applications, e. g. wireless links in data centers.
The current IEEE Std. 802.15.3d-2017 covers the frequency bands 252 to $321 \mathrm{GHz}$. Thereof, two potential future activities may be triggered in the context of this standard:

1. The continuing use of the frequency bands $296-306 \mathrm{GHz}$ and $313-318 \mathrm{GHz}$ by this standard will be possible, if additional sharing studies in accordance with Resolution 731 (Rev.WRC-19) show that no harmful interference to EESS occurs. This may trigger a potential regulatory activity towards WRC 2023.

2. In order to make use of the large chunk of spectrum between $356 \mathrm{GHz}$ and $450 \mathrm{GHz}$, an amendment to IEEE 802.15.3d-2017 will be necessary and may trigger standardization activities at IEEE 802.

The potential agenda item at WRC 2027 on the identification of spectrum for radio location applications in the range 275-700 $\mathrm{GHz}$ will require sharing studies with $\mathrm{THz}$ communications as the incumbent application. This may trigger another potential regulatory activity towards WRC 2027.

\section{CONCLUSIONS}

In this paper, the outcome of WRC 2019 w.r.t. THz communications is described. WRC 2019 has added a new footnote to the radio regulations, which describes the conditions for the use of the spectrum between 275 and $450 \mathrm{GHz}$ by land mobile and fixed services. Totally, $160 \mathrm{GHz}$ of spectrum are now available for $\mathrm{THz}$ communications, where no specific conditions are necessary to protect EESS. This includes two big contiguous spectrum bands with $44 \mathrm{GHz}$ and $94 \mathrm{GHz}$ bandwidth, respectively. This provides a sound basis for the future implementation of $\mathrm{THz}$ communications. Still, a couple of future regulatory and standardization activities have been identified.

\section{ACKNOWLEDGEMENT}

The results presented in this contribution have been achieved within the ThoR project. This project has received funding from Horizon 2020, the European Union's Framework Programme for Research and Innovation, under grant agreement No. 814523. ThoR has also received funding from the National Institute of Information and Communications Technology in Japan (NICT).

\section{REFERENCES}

[1] IEEE Standard for High Data Rate Wireless Multi-Media Networks-Amendment 2: $100 \mathrm{~Gb} / \mathrm{s}$ Wireless Switched Point-to-Point Physical Layer," in IEEE Std 802.15.3d-2017 (Amendment to IEEE Std 802.15.32016 as amended by IEEE Std 802.15.3e-2017), pp.1-55, Oct. 18, 2017.

[2] World Radiocommunication Conference, ,,Radio Regulations, Edition of 2016,“ [Online]. Available: https://www.itu.int/pub/R-REG-RR.

[3] S. Rey, Initial results on sharing studies, ThoR Deliverable D5.1; available at https://thorproject.eu/results/

[4] RESOLUTION 767(WRC-15): Studies towards an identification for use by administrations for land-mobile and fixed services applications operating in the frequency range $275-450 \mathrm{GHz}$ [Online]. Available: https://www.itu.int/dms pub/itur/oth/0c/0a/R0C0A00000C0016PDFE.pdf

[5] ITU-R, „Recommendation ITU-R RS.2017: Performance and interference criteria for satellite passive remote sensing," [Online]. Available: https://www.itu.int/rec/R-REC-RS.2017/en. 
[6] ITU-R, „Report ITU-R F.2416: Technical and operational characteristics and applications of the point-to-point fixed service applications operating in the frequency band 275-450 GHz," [Online]. Available: https://www.itu.int/pub/R-REP-F.2416.

[7] T. Kürner, Regulatory Aspects of $\mathrm{THz}$ Communications and Related Activities Towards WRC 2019, Proc. European Conference on Networks and Communications, 18-21 Jun-2019; Valencia, Spain; electronic (2 pages), [online] https://doi.org/10.24355/dbbs.084-201908211524-0.

[8] Priebe, S.; Britz, D. M.; Jacob, M.; Sarkozy, S.; Leong, K. M. K.; Logan, J. E.; Gorospe, B.; Kürner, T.: Interference Investigations of Active
Communications and Passive Earth Exploration Services in the $\mathrm{THz}$ Frequency Range. IEEE Transactions on Terahertz Science and Technology, Vol. 2, No. 5, pp. 525- 537, 2012.

[9] A. Clegg, Sharing between radio astronomy and active services at $\mathrm{THz}$ frequencies, [online] https://mentor.ieee.org/802.15/dcn/10/15-10-082900-0thz-sharing-between-active-and-passive-services-at-thzfrequencies.ppt

[10] World Radiocommunication Conference 2019 (WRC-19) Final Acts; [online]: https://www.itu.int/dms_pub/itu-r/opb/act/R-ACT-WRC.142019-PDF-E.pdf 